\title{
The risk factors on the prognosis of pulmonary embolism in tumor patients after the thoracic and abdominal surgery
}

\author{
Ren-Xiong Chen, Hong-Zhi Wang^, Yong Yang, Xiao-Jie Chen^^ \\ ICU Department, Key Laboratory of Carcinogenesis and Translational Research (Ministry of Education/Beijing), Peking University Cancer Hospital \\ \& Institute, Beijing, China \\ Contributions: (I) Conception and design: RX Chen, HZ Wang; (II) Administrative support: RX Chen, HZ Wang; (III) Provision of study materials \\ or patients: Y Yang, XJ Chen; (IV) Collection and assembly of data: RX Chen, Y Yang, XJ Chen; (V) Data analysis and interpretation: RX Chen, HZ \\ Wang; (VI) Manuscript writing: All authors; (VII) Final approval of manuscript: All authors \\ Correspondence to: Hong-Zhi Wang, MD. ICU Department, Key Laboratory of Carcinogenesis and Translational Research (Ministry of Education/Beijing), \\ Peking University Cancer Hospital \& Institute, No. 52 of Fucheng Road, Haidian District, Beijing 100142, China. Email: wanghz58@sina.com.
}

\begin{abstract}
Background: We studied the clinical profiles and the risk factors on the prognosis of tumor patients with pulmonary embolism (PE) after the thoracic and abdominal surgery

Methods: We retrospectively screened patients who underwent the thoracic and abdominal surgery at the Peking University Cancer Hospital from January 1, 2007 to January 1, 2020. Among them, 115 patients who were diagnosed with PE were enrolled in our study. Cox regression was performed for multivariate adjusted factor analyses.

Results: The 90-day overall mortality rate was $11.3 \%$ in our study. Univariate analysis showed that gender, MPV, shock, oxygenation index and the APACHE II score within 24 hours after diagnosis of PE were statistically significant in the prognosis of $\mathrm{PE}$ after the thoracic and abdominal surgery. In multiple cox regression analysis, we found that patients with shock and the APACHE II score within 24 hours after diagnosis of $\mathrm{PE}$ were independent risk factors on the prognosis of $\mathrm{PE}$ after the thoracic and abdominal surgery (P values of 0.020 and 0.014 , respectively).

Conclusions: Shock and the APACHE II score within 24 hours after diagnosis of PE were independent risk factors on the prognosis of PE after the thoracic and abdominal surgery; however, the study power was limited.
\end{abstract}

Keywords: risk factors; pulmonary embolism (PE); tumor patients; surgery

Submitted Feb 27, 2020. Accepted for publication Jul 14, 2020.

doi: 10.21037/apm-20-494

View this article at: http://dx.doi.org/10.21037/apm-20-494

\section{Introduction}

Pulmonary embolism (PE), one nightmare of some clinicians, is a global issue. Pulmonary embolism-related mortality in the USA might outnumber myocardial infarction-related and stroke-related mortality (1). In China, one study reported that the overall annual incidence of $\mathrm{PE}$ was 11.7 per 100,000 persons, and the hospital mortality rate of $\mathrm{PE}$ was $17.4 \%$ (2). Many factors might increase the likelihood of PE. Surgery and tumors were the risk factors of venous thromboembolism (3). The incidence rate of PE was very high in tumor patients. Previous researches showed that the tumors might produce some substances resulting in thrombin generation $(4,5)$.

Therapy for patients with PE after surgery was more complicated than for PE patients without surgery due to the high-risk rate of bleeding (6). The aim of this study was to

^ ORCID: Ren-Xiong Chen, 0000-0003-0471-3449; Hong-Zhi Wang, 0000-0003-0985-2157. 
Table 1 Baseline characteristics of patients with PE

\begin{tabular}{|c|c|}
\hline Items & Values \\
\hline Age, median (range) & 65 (44 to 82$)$ \\
\hline \multicolumn{2}{|l|}{ Sex, n (\%) } \\
\hline Male & $57(49.6)$ \\
\hline Female & $58(50.4)$ \\
\hline Body mass index, mean (SD), kg/m² & $25.8(3.5)$ \\
\hline \multicolumn{2}{|l|}{ Tumor location, n (\%) } \\
\hline Abdominal tumor & $52(45.2)$ \\
\hline Thoracic tumor & $36(31.3)$ \\
\hline Breast cancer & $27(23.5)$ \\
\hline \multicolumn{2}{|l|}{ Coexisting conditions ${ }^{\star}, \mathrm{n}(\%)$} \\
\hline Hypertension & $49(42.6)$ \\
\hline Diabetes & $20(17.4)$ \\
\hline Coronary heart disease & $10(8.7)$ \\
\hline Arrhythmia & $7(6.1)$ \\
\hline thyroid disease & $10(8.7)$ \\
\hline Varicose vein of lower limb & $13(11.3)$ \\
\hline Accompanying infection & $26(22.6)$ \\
\hline \multicolumn{2}{|l|}{ ABO blood type, n (\%) } \\
\hline O type & $37(32.2)$ \\
\hline A type & $40(34.8)$ \\
\hline B type & $28(24.3)$ \\
\hline AB type & $10(8.7)$ \\
\hline
\end{tabular}

*, 29 patients had more than one coexisting condition.

explore the clinical profiles and risk factors on the prognosis of tumor patients with PE after the thoracic and abdominal surgery.

We present the following article in accordance with the STROBE reporting checklist (available at http://dx.doi. org/10.21037/apm-20-494).

\section{Methods}

\section{Study population}

Patients who underwent thoracic and abdominal surgery for the treatment of tumors at Peking University Cancer Hospital from January 1, 2007 to January 1, 2020 were retrospectively screened. The study was conducted in accordance with the Declaration of Helsinki (as revised in 2013). This study was approved by the Institutional Review Board of Peking University Cancer Hospital (No. 2016KT18) and informed consent was taken from all the patients or their next of kin. The diagnosis of PE was done according to the ACCP (American College of Chest Physicians) guidelines $(7,8)$. A total of 115 patients were included for analysis in this study. Low molecular weight heparin anticoagulant therapy was utilized in our hospital for patients with moderate and low risk PE after surgery. For patients with high-risk PE, we used thrombolysis or anticoagulation according to the risk rate of bleeding. The anticoagulant treatment period was at least three months.

\section{Statistical analyses}

The results were described as the median (range) or numbers (percentage). They were followed up for 90 days by the clinic or by phone call. Kaplan-Meier method was used to calculate the survival rate of patients, and Log-rank test was used for the univariate analysis. Cox regression was used for the multivariate adjusted factor analyses and forward LR was performed. Statistical analyses were carried out using SPSS Version 23.0 and $\mathrm{P}$ values less than 0.05 (two-tailed) were considered significant.

\section{Results}

\section{Patient characteristics}

Among them, 110 patients were diagnosed with PE by computed tomographic pulmonary angiography (CTPA) examination with a filling defect. Five patients were diagnosed by lower limb venous ultrasonography with decreased peripheral arterial oxygen saturation because CTPA was improper for these patients. The median time to diagnosis of $\mathrm{PE}$ was three days after operation, 59 cases were accompanied by deep-vein thrombosis of lower extremity, six cases by deep-vein thrombosis of upper extremity. There were 25 asymptomatic patients in our study. The baseline characteristics of these included patients are shown in Table 1.

When the diagnosis of PE was done every patient was given oxygen therapy. Fourteen patients needed tracheal intubation; four patients used non-invasive ventilatorassisted breathing firstly (two patients improved and the other two patients finally advanced to intubation).

Among them, three patients were, firstly, given 
Table 2 Univariate survival analysis of patients with PE

\begin{tabular}{|c|c|c|c|}
\hline Groups & Number (\%) & $\begin{array}{l}\text { Survival rate } \\
\text { at } 90 \text { days }\end{array}$ & $P$ value \\
\hline Age, years & & & 0.861 \\
\hline$\leq 65$ & $51(44.3)$ & 0.882 & \\
\hline$>65$ & $64(55.7)$ & 0.891 & \\
\hline Sex & & & 0.035 \\
\hline Male & $57(49.6)$ & 0.825 & \\
\hline Female & $58(50.4)$ & 0.946 & \\
\hline $\mathrm{BMI}, \mathrm{kg} / \mathrm{m}^{2}$ & & & 0.168 \\
\hline$\leq 25$ & $58(50.4)$ & 0.845 & \\
\hline$>25$ & $57(49.6)$ & 0.930 & \\
\hline Platelets, $10^{\circ} / \mathrm{L}$ & & & 0.300 \\
\hline$\leq 150$ & $38(33.0)$ & 0.842 & \\
\hline$>150$ & $77(67.0)$ & 0.909 & \\
\hline Mean platelet volume, $\mathrm{fL}$ & & & 0.017 \\
\hline$\leq 10$ & $54(47.0)$ & 0.963 & \\
\hline$>10$ & $61(53.0)$ & 0.820 & \\
\hline Fibrinogen, $\mathrm{g} / \mathrm{L}$ & & & 0.052 \\
\hline$\leq 400$ & $50(43.5)$ & 0.820 & \\
\hline$>400$ & $65(56.5)$ & 0.938 & \\
\hline D-Dimer, mg/L & & & 0.052 \\
\hline$\leq 5$ & $64(55.7)$ & 0.938 & \\
\hline$>5$ & $51(44.3)$ & 0.824 & \\
\hline Shock & & & 0.001 \\
\hline Yes & $12(10.4)$ & 0.417 & \\
\hline No & $103(89.6)$ & 0.942 & \\
\hline Oxygenation index, $\mathrm{mmHg}$ & & & 0.017 \\
\hline$\leq 200$ & $71(61.7)$ & 0.831 & \\
\hline$>200$ & $44(38.3)$ & 0.977 & \\
\hline APACHEII score & & & 0.001 \\
\hline$\leq 15$ & $89(77.4)$ & 0.966 & \\
\hline$>15$ & $26(22.6)$ & 0.615 & \\
\hline Tumor type & & & 0.222 \\
\hline Abdominal tumor & $52(45.2)$ & 0.846 & \\
\hline $\begin{array}{l}\text { Thoracic tumor and } \\
\text { breast cancer }\end{array}$ & $63(54.8)$ & 0.921 & \\
\hline
\end{tabular}

urokinase or recombinant tissue plasminogen activator (rt-PA) for intravenous thrombolysis and sequentially they were administered nadroparin calcium. The other patients received anticoagulants (nadroparin calcium) as an initial therapy. Owing to the high-risk rate of bleeding after operation, about half of these patients in the group received a reduced dosage of anticoagulant drugs. During the treatment, a total of five patients had major bleeding. Twelve patients had clinically relevant non-major bleeding and were adjusted to a reduced dosage of anticoagulation agents. These patients recovered from bleeding luckily after decreased the dosage of anticoagulation therapy and/or given a blood transfusion.

\section{The univariate and multiple survival analyses}

The patients in this study were followed up for 90 days by the clinic or by phone call, and no patient was lost to follow up. In this study, the 90 -day mortality rate was $11.3 \%$. The cause of death was multiple organ failures caused by PE except one case with infection. Univariate analysis showed that gender, MPV(mean platelet volume), shock (systolic blood pressure less than $90 \mathrm{mmHg}$, or the blood pressure of patients with hypertension dropped more than 20\%), oxygenation index and APACHEII score within 24 hours after diagnosis were statistically significant, while age, BMI, platelets, fibrinogen, D-dimer within 24 hours after diagnosis and tumor type were not statistically significant. See Table 2 for details.

Five factors with statistical difference in univariate analysis were put into multivariate cox regression analysis. The results showed that shock and APACHEII score greater than 15 within 24 hours after diagnosis were independent prognostic factors of $\mathrm{PE}$, with RR values of 4.674 and 6.847 respectively. See Table 3 for details. The survival curves of these two factors are shown in Figures 1,2.

\section{Discussion}

The clinical manifestations of PE were not specific and some patients were asymptomatic (9). PE should be alert when the patient has dyspnea, chest pain, syncope, or hemoptysis. There were few patients with circulatory failure, but once circulatory failure occurred, especially in patients with respiratory and cardiac arrest; it indicated a poor prognosis. Until now, the most commonly method utilized for diagnosis of PE was CTPA. However, when 
Table 3 Multivariate survival analysis of patients with $\mathrm{PE}$

\begin{tabular}{lccc}
\hline Risk factors & $\mathrm{RR}$ & $95 \% \mathrm{Cl}$ & $\mathrm{P}$ value \\
\hline Shock & 4.674 & $1.274-17.143$ & 0.020 \\
APACHEll score $>15$ & 6.847 & $1.485-31.579$ & 0.014 \\
\hline
\end{tabular}

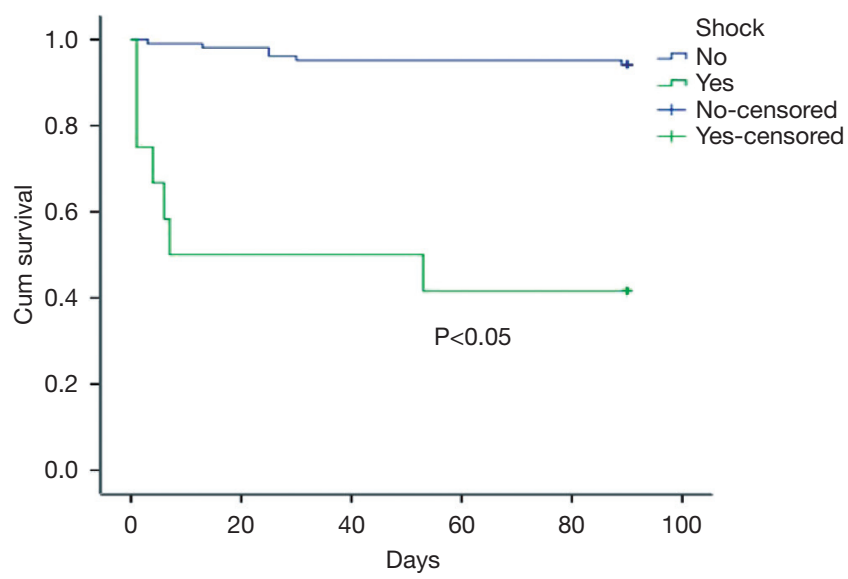

Figure 1 Kaplan-Meier survival curve of overall survival about shock within 24 hours after diagnosis of PE.

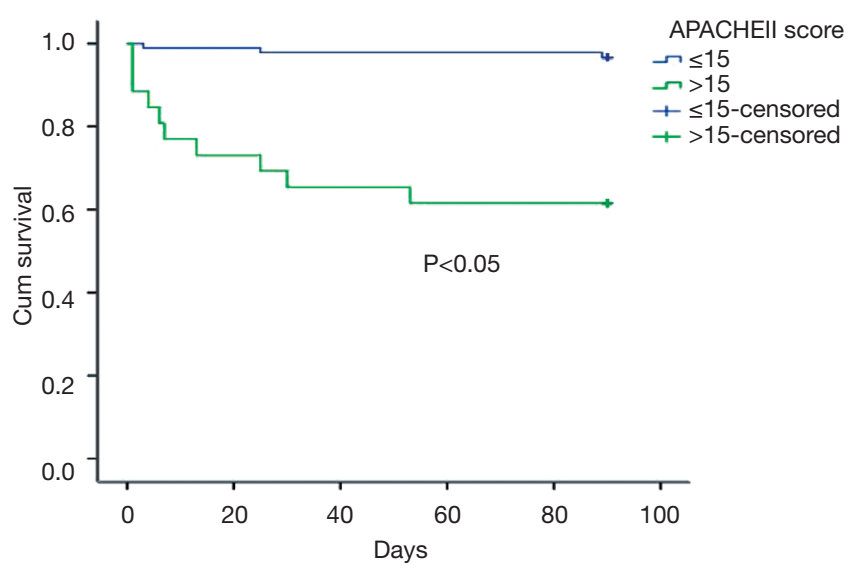

Figure 2 Kaplan-Meier survival curve of overall survival about APACHEII score within 24 hours after diagnosis of PE.

CTPA was not safe for the patients, bedside B-mode ultrasonography was recommended as an option (7-9). Five patients in this study were diagnosed according to the consequences of B ultrasound.

For high-risk $\mathrm{PE}$, thrombolytic therapy was recommended in the guidelines $(7,8)$. However, if this appeared after surgery, thrombolytic therapy needed to be careful due to the high-risk rate of bleeding. In this study, five patients were initially handled by thrombolytic therapy. The role of fibrinolysis therapy in patients with intermediate-risk PE was still controversial (10). It might increase the risk of major bleeding. In our hospital, we used anticoagulant agent (nadroparin calcium) in intermediate and low risk PE patients. In this study, there were five patients had major bleeding and twelve patients experienced clinically relevant non-major bleeding during anticoagulation therapy. Although these bleeding patients eventually improved, the overall bleeding rate was still high, which was worth pondering. It was reported that bleeding was related to older age, metastatic tumor, recent history of massive hemorrhagic disease, abnormal prothrombin time, anemia, renal insufficiency, etc. (11). Up to now, one direct thrombin inhibitor and three factor Xa inhibitors were adopted for the treatment of VTE and became popular in many countries. They had been proved to be as safe and effective for the treatment of acute VTE by related research $(12,13)$, and they did not require any coagulation function monitoring. However, the disadvantage said there was no related antagonist for them if bleeding occurred.

The 3-month overall mortality rate was reported to be about $15 \%$ to $18 \%$ and shock increased mortality by two to six times (14). The systolic blood pressure, brain natriuretic peptide and cardiac troponin were reported to be associated with the prognosis of PE patients (15-17). Yardan et al. (18) reported that higher MPV and MPV/PLT ratio were associated with poor prognosis in patients with acute PE. In our study, the univariate analysis showed that gender, MPV, shock, oxygenation index and APACHE II score within 24 hours after diagnosis were statistically significant; however, only shock and APACHE II score greater than 15 within 24 hours after diagnosis were independent prognostic factors in the multivariate analysis.

In our study, some limitations should be referred. First, this study was a retrospective study and only talked about PE patients after the thoracic and abdominal tumor surgery, so these results might not extend to all surgical patients. Second, many data were lost especially data regarding the ultrasound cardiogram; however, this did not influence our final therapy decision. Third, the morbidity of PE may have been underestimated because not all patients in our study underwent CTPA. Finally, the sample size in our analysis was small and the power was limited. In future, more studies are needed to confirm the results. 


\section{Conclusions}

Shock and the APACHE II score within 24 hours after diagnosis of $\mathrm{PE}$ were independent risk factors on the prognosis of $\mathrm{PE}$ after the thoracic and abdominal surgery; however, the study power was limited.

\section{Acknowledgments}

Funding: The study was funded by B. Braun Anaesthesia Science Research Foundation (BBFD-2015-16).

\section{Footnote}

Reporting Checklist: The authors have completed the STROBE reporting checklist (available at http://dx.doi. org/10.21037/apm-20-494).

Data Sharing Statement: Available at http://dx.doi. org/10.21037/apm-20-494

Peer Review File: Available at http://dx.doi.org/10.21037/ apm-20-494

Conflicts of Interest: All authors have completed the ICMJE uniform disclosure form (available at http://dx.doi. org/10.21037/apm-20-494). The authors have no conflicts of interest to declare.

Ethical Statement: The authors are accountable for all aspects of the work in ensuring that questions related to the accuracy or integrity of any part of the work are appropriately investigated and resolved. The study was conducted in accordance with the Declaration of Helsinki (as revised in 2013). The study was approved by the Institutional Review Board of Peking University Cancer Hospital (No. 2016KT18) and informed consent was taken from all the patients or their next of kin.

Open Access Statement: This is an Open Access article distributed in accordance with the Creative Commons Attribution-NonCommercial-NoDerivs 4.0 International License (CC BY-NC-ND 4.0), which permits the noncommercial replication and distribution of the article with the strict proviso that no changes or edits are made and the original work is properly cited (including links to both the formal publication through the relevant DOI and the license). See: https://creativecommons.org/licenses/by-nc-nd/4.0/.

\section{References}

1. Giordano NJ, Jansson PS, Young MN, et al. Epidemiology, Pathophysiology, Stratification, and Natural History of Pulmonary Embolism. Tech Vasc Interv Radiol 2017;20:135-40.

2. Law Y, Chan YC, Cheng SWK. Epidemiological updates of venous thromboembolism in a Chinese population. Asian J Surg 2018;41:176-82.

3. Aggarwal A, Fullam L, Brownstein AP, et al. Deep vein thrombosis (DVT) and pulmonary embolism (PE): awareness and prophylaxis practices reported by patients with cancer. Cancer Invest 2015;33:405-10.

4. Thaler J, Ay C, Pabinger I. Clinical significance of circulating microparticles for venous thromboembolism in cancer patients. Hamostaseologie 2012;32:127-31.

5. Date K, Ettelaie C, Maraveyas A. Tissue factor-bearing microparticles and inflammation: a potential mechanism for the development of venous thromboembolism in cancer. J Thromb Haemost 2017;15:2289-99.

6. Chen RX, Wang HZ, Dong J, et al. Pulmonary embolism in non-brain tumor patients after surgery-a retrospective study in China. World J Surg Oncol 2017;15:22.

7. Gould MK, Garcia DA, Wren SM, et al. Prevention of VTE in nonorthopedic surgical patients: Antithrombotic Therapy and Prevention of Thrombosis, 9th ed: American College of Chest Physicians Evidence-Based Clinical Practice Guidelines. Chest 2012;141:e227S-77S.

8. Kearon C, Akl EA, Ornelas J, et al. Antithrombotic Therapy for VTE Disease: CHEST Guideline and Expert Panel Report. Chest 2016;149:315-52.

9. Kruger PC, Eikelboom JW, Douketis JD, Hankey GJ. Pulmonary embolism: update on diagnosis and management. Med J Aust 2019;211:82-7.

10. Meyer G, Vicaut E, Danays T, et al. Fibrinolysis for patients with intermediate-risk pulmonary embolism. $\mathrm{N}$ Engl J Med 2014;370:1402-11.

11. Monreal M. Fatal pulmonary embolism or bleeding in patients with venous thromboembolism: implications of real-life data. Thromb Res 2019;181 Suppl 1:S6-9.

12. Howard LS. Non-vitamin $\mathrm{K}$ antagonist oral anticoagulants for pulmonary embolism: who, where and for how long? Expert Rev Respir Med 2018;12:387-402.

13. Almutairi AR, Zhou L, Gellad WF, et al. Effectiveness and Safety of Non-vitamin K Antagonist Oral Anticoagulants for Atrial Fibrillation and Venous Thromboembolism: A Systematic Review and Meta-analyses. Clin Ther 2017;39:1456-78.e36. 
14. Tapson VF. Acute pulmonary embolism. N Engl J Med 2008;358:1037-52.

15. El-Menyar A, Sathian B, Al-Thani H. Elevated serum cardiac troponin and mortality in acute pulmonary embolism: Systematic review and meta-analysis. Respir Med 2019;157:26-35.

16. Bajaj A, Rathor P, Sehgal V, et al. Prognostic Value of Biomarkers in Acute Non-massive Pulmonary Embolism: A Systematic Review and Meta-analysis. Lung
2015;193:639-51.

17. Tong C, Zhang Z. Evaluation factors of pulmonary embolism severity and prognosis. Clin Appl Thromb Hemost 2015;21:273-84.

18. Yardan T, Meric M, Kati C, et al. Mean platelet volume and mean platelet volume/platelet count ratio in risk stratification of pulmonary embolism. Medicina (Kaunas) 2016;52:110-5.
Cite this article as: Chen RX, Wang HZ, Yang Y, Chen XJ. The risk factors on the prognosis of pulmonary embolism in tumor patients after the thoracic and abdominal surgery. Ann Palliat Med 2020;9(5):2982-2987. doi: 10.21037/apm-20-494 